\title{
Chromatographic methods used for characterization of boswellic acids
}

\begin{abstract}
Utilization of natural herbs and their drug products have been extensively increases worldwide because of lesser side effects of natural origin-based products in contrast with synthetic products. Gum resin of plant Boswellia serrata constitutes the major constituents Boswellic acids which are pentacyclic triterpenoids belonging to ursane group. Herbal medicines composed of various constituents and suffer from constraints of variability in their compositions. In order to make availability of herbal drugs, various chemical and instrumental methods have been used at regular intervals for the standardization and characterization of herbal drugs. Chromatography is very popular and mostly employed analytical technique for standardization and the separation of mixture of constituent's in herbal drug products. Current manuscript provides concise overview and trends of separation, identification and quantification of boswellic acids by modern chromatographic techniques including HPLC, HPTLC and LC/MS with significant research studies.
\end{abstract}

Keywords: boswellic acids, characterization, HPLC, HPTLC, LC/MS
Volume 2 Issue 4 - 2018

\section{Dureja Harish, Neeta Solanki}

Department of Pharmaceutical Sciences, Maharshi Dayanand University, India

\begin{abstract}
Correspondence: Harish Dureja, Department of Pharmaceutical Sciences, Maharshi Dayanand University, India, Tel+9I-94I6357995, Email harishdureja@gmail.com
\end{abstract}

Received: June 26, 2018 | Published: July II, 2018

\section{Introduction}

Herbal medicines obtained from plants are an important source for discovery and development of new therapeutically active agents. Herbal products still remain as one of the best reservoirs of new drug molecules to make them available by using different approaches. The standardization is valuable tool for qualitative and quantitative estimation of plant extracts, which provides wide variety of prospective for novel drug molecules. ${ }^{1}$ Despite the continuous advancements in area of medicinal field, public interest and acceptance towards herbal drug products in both developing and developed countries is increasing. World Health Organization (WHO) has made estimation that approximately $80 \%$ of the population globally still uses natural medicines and natural source based medicines for their primary health care. Herbal medicine and their preparations have been widely used for the thousands of years in developing and developed countries owing to its natural origin and lesser side effects or dissatisfaction with the results of synthetic drugs. ${ }^{2-3}$ Herbal medicines continuously contributing an important role in production of new active agents as clinically effective therapeutic agents including starting materials to produce synthetic drugs. ${ }^{4}$ Herbal products have reached widespread acceptability as therapeutic agents for various complex and lifethreatening diseases. ${ }^{5-6}$ Boswellia serrata plant belonging to the family Burseracea is one of the medicinal plants of the genus Boswellia and approximately about 20 species are known for their medicinal value. ${ }^{7-8}$ An oleo-gum-resin obtained from Boswellia serrata BS (Salai guggal) also known as Frankincense (English) and Olibanum (Arabian). In India $B$ serrata occurs in the dry hilly forests of Bihar, Madhya Pradesh, Gujarat, Rajasthan etc. Documented literature revealed the highly accepted medicinal applications for various diseases including cancer, inflammation, arthritis, asthma and hyperlipidemia. Among all species of genus Boswellia, B serrata is the most investigated in terms of phytochemical and bioactivity related studies. ${ }^{9}$ Major phyto constituents of gum resin of Boswellia plant are Boswellic acids (BAs) with the molecular formulas of $\mathrm{C}_{32} \mathrm{H}_{52} \mathrm{O}_{4}$ (pentacyclic triterpenoids) belongs to ursane group. ${ }^{10} \beta$ boswellic acid (BBA), acetyl- $\beta$-boswellic acid (ABBA), $11-$ keto- $\beta$ - boswellic acid (KBA) and 3-O-acetyl-11-keto- $\beta$ boswellic acid (AKBA) are well reported four main BAs, among them AKBA have good therapeutic value for anti-inflammatory diseases, anticancer, anti-arthritis, bronchial asthma, chronic colitis, ulcerative colitis. ${ }^{11-14}$

\section{Need of phytochemical analysis}

Assurance of quality, efficacy and safety of natural products has become crucial parameters for commercial acceptability of plant products in modern system of medicine. Genotypic, ecotypic drying and storage conditions variations of natural raw materials leads to variations in the constituents present in herbal drug product. Therefore, quantitative and qualitative characterization of herbal raw products, estimation of the biomarkers and/ or different chemical marker compounds and determination of fingerprinting profiles is necessary for adequate supply of phyto constituents. Both qualitative and quantitative analysis is done where an active constituent is not known, standard marker compound could be chosen for analysis use which should be specific for the particular active compound. In case, if therapeutically active constituent present in herbal raw extract is known then quantification of this compound is important characterization parameter from analytical point of view. ${ }^{6,15}$ Selection of particularly effective standardization technique should take in to consideration which may affect assessment of the quality and quantity of constituents of the natural plant products. Today, modern analytical chemistry involves utilization of advanced analytical instruments for standardization of herbal drugs. ${ }^{16,17}$ Drug discovery and development process includes modern scientific investigation at every step such as analysis of biological samples, bulk drug materials, intermediates of drug products, marketed products, formulations, impurities and degradation products. ${ }^{15,18}$

\section{Different constraints affecting the quality of herbal drugs}

a) Generally, mixture of different constituents is present within the raw plant extract. 
b) Suitable analytical technique or standard marker compounds may not available commercially.

c) Mostly the active constituent is not known.

d) Chemical and natural variations affect the quality of herbal products.

e) Various factors such as harvesting method, drying, transportation, storage, and processing parameters including extraction technique and polarity of the solvent, extraction temperature etc. have great impact on quality and quantity of herbal drugs. Thus, for assurance of repeatability and reliability of phyto constituents of natural drug products and to identify their therapeutic activities and side effects it becomes necessary to develop suitable analytical approach for pharmacological and clinical research. Various chromatographic and spectrophotometric methods have been used for qualitative and quantitative analysis herbal medicines. ${ }^{19}$

\section{Chromatographic analysis}

Chromatography is mostly used suitable analytical technique to separate different compounds of a mixture on the basis of differences in their structural composition. Basic principle of this technique involves application of mixture of compounds to be separated over a stationary phase and different compounds have different interactions on the basis of their structural composition with the stationary support. Separating compounds which have greater affinity towards the stationary phase will move slowly while other having low affinity will move faster. Depending upon the affinity of test compounds towards stationary support a mixture of compounds can be separated from each other as they move over the stationary support. ${ }^{19}$ Different stationary phases and mobile phases used in chromatography are represented in Table 1.

\section{Thin layer chromatography}

Thin Layer Chromatography (TLC) is one of the simple and most popularly employed chromatographic techniques for separation of a wide variety of organic and inorganic materials. TLC is effective fingerprint technique for both qualitative and semi quantitative in area of herbal drug technology. Generally, finely powdered alumina or silica particles adsorbent (polar absorbent), is coated onto a glass, plastic plate in the form of thin layer and mobile phase can be consists of a single solvent or combination of solvents. ${ }^{20-23}$ Organic compounds can be separated by changing ratio of different solvents and a number of solvent mixtures can be utilized as the mobile phase for separation. Efficiency of chromatographic separation depends on various factors such as separating molecules selectivity towards adsorbent, which ultimately results in differences in the rate of elution of the substance from the mixture.

\section{Advantages of thin layer chromatography}

- Rapid analysis of herbal drug extracts with minimum sample clean-up requirement

- Effective approach for screening of unknown materials in bulk drugs

- TLC analysis gives qualitative and semi quantitative information

- Reaction progress can be monitored

- Determination of pharmaceuticals impurities
- A variety of solvents can be use

- Flexibility in sample distinction

- Effective technique to provide information in the early stage of drug development

- Low cost

Table I Commonly used stationary phase and mobile phase with increasing polarity

\begin{tabular}{|c|c|}
\hline Stationary phase & Mobile phase \\
\hline Polydimethylsiloxane & Helium \\
\hline Methyl/Phenyl siloxane & Nitrogen \\
\hline Cyanopropyl siloxane & Petroleum ether (pentanes) \\
\hline Carbowaxes (Polyethylene glycol) & Hexanes \\
\hline Hydrocarbon-coated silica e.g. C-18 & Cyclohexane \\
\hline Paper & Carbon tetrachloride \\
\hline Cellulose & Toluene \\
\hline Starch & Chloroform \\
\hline Calcium sulfate & $\begin{array}{l}\text { Dichloromethane (methylene } \\
\text { chloride) }\end{array}$ \\
\hline Silica (silica gel) & $\mathrm{t}$-Butyl methyl ether \\
\hline Florisil (magnesium silicate) & Diethyl ether \\
\hline Magnesium oxide & Ethyl acetate \\
\hline $\begin{array}{l}\text { Alumina (aluminum oxide; acidic, } \\
\text { basic or neutral) }\end{array}$ & Aniline \\
\hline Activated carbon & Acetonitrile \\
\hline$C-18(250 \mathrm{~cm} \times 4.6 \mathrm{~mm} \times 5 \mu \mathrm{m})$ & $\begin{array}{l}0.1: 99.9 \mathrm{v} / \mathrm{v} \text { (Phosphoric } \\
\text { acid:Water) and } 0.1: 99.9 \mathrm{v} / \mathrm{v} \\
\text { (Phosphoric acid:Acetonitrile }\end{array}$ \\
\hline Kromasil $100 \mathrm{Cl} 8$ & Acetonitrile: water $(90: 10 \mathrm{v} / \mathrm{v})$ \\
\hline RP-I8 column $(2.1 \times 100 \mathrm{~mm}, 1.7 \mu \mathrm{m})$ & $\begin{array}{l}\text { Acetonitrile: water ( } 0.1 \% \text { Acetic } \\
\text { acid) }\end{array}$ \\
\hline $\begin{array}{l}\text { RP-18, Merck column }(4 \times 250 \mathrm{~mm} \text {, } \\
5 \mu \mathrm{m}\end{array}$ & $\begin{array}{l}\text { Acetonitrile: } 0.5 \% \text { acetic acid in } \\
\text { water ( } 95: 5)\end{array}$ \\
\hline RP CI 8 column $(100 \times 4 \mathrm{~mm} ; 3 \mu \mathrm{m}$ & $\begin{array}{l}\text { Mobile phase } A \text { (methanol: water } \\
90: 10,400 \mathrm{mg} / \mathrm{L} \text { ammonium } \\
\text { formate) and mobile phase } B \\
\text { (methanol: water } 80: 20,400 \mathrm{mg} / \mathrm{L} \\
\text { ammonium formate) }\end{array}$ \\
\hline- & Ethanol \\
\hline- & Methanol \\
\hline- & Water \\
\hline- & Acetic acid \\
\hline
\end{tabular}

Depending upon structural composition of compounds present within mixture some compounds strongly adsorbed on the adsorbent while others adsorbed poorly. An ideal solvent system used for chromatographic separation should travel all compounds of the mixture off the baseline, but does not put anything on the solvent front. Retention factor value of compounds should resolve between 0.15 and 0.85. Polar or non-polar nature of the mobile phase provides eluent 
strength which affects the elution power of the mobile phase. Faster will be elution of the separating compound if compound have higher non polar nature because of poor affinity towards stationary phase or less time it will remain on the stationary phase. ${ }^{24-27}$ have conducted pharmacognostical study of counting both macroscopic and powder microscopy of oleo gum resin of plant BS. TLC was carried out on different extractive samples after selection of appropriate solvent system for confirmation of presence of certain constituents in the extract. The spots obtained from both the extracts were observed under UV light of wavelength $254 \mathrm{~nm}$ and $366 \mathrm{~nm}$. TLC confirmed the presence of different constituents in the test samples and is helpful for easy preliminary identification of phyto chemicals in the drug samples. $^{28}$

\section{High performance thin layer chromatography}

Increasing advancements towards instrumental analysis high performance thin layer chromatography (HPTLC) arises as promising technique for rapid separation with flexibility for analysis a range of samples. Different samples can be analyzed simultaneously by using less amount of mobile phase as compared with High Performance Liquid Chromatography. HPTLC have number of advantages as it requires less time for analysis of crude or complex samples, easy to handle. Variety of analysis parameters can be evaluated by use of entire chromatogram without time limits. Simultaneously different samples and standards can be developed on each plate. This is effective technique to provide reliable results of test samples. ${ }^{29,30}$ Chromatogram can be repeatedly scanning under same or different conditions by HPTLC. Multi compound formulation has been simultaneously assayed by this technique. HPTLC is advanced tool for authentication, consistency and stability analysis of plants along with their preparation from different manufacturers. ${ }^{31,32}$

\section{Salient features of HPTLC as analytical technique}

It shows better accuracy and precision for simultaneously processing of both sample and standard compounds.

a) Different samples analyzed at same time.

b) Economical process for analysis of different samples as low maintenance cost.

c) Pre-treatment like filtration and degassing is not required for solvents used and sample preparation is simple for different nature samples.

d) Low mobile phase consumption per sample.

e) There is no contamination occurs and free from interference of previous analysis.

f) HPTLC is an open system make availability of visual detection.

g) Compounds having absorption in UV resgion detected by post chromatographic derivatization. ${ }^{33-36}$

Significant research work has been done in the arena of characterization of BAs. Here, we are describing some of the endeavor related to characterization of BAs by different chromatographic techniques. Conducted comparative analysis of HPTLC and HPLC for the estimation of KBA and AKBA in gum resin extract. Purity of KBA and AKBA was determined by UV detection assays by comparison of peaks obtained from test samples with standard marker compounds. Data obtained for the study revealed that there was no significant difference in results of both analytical methods between content of KBA and AKBA, and a slightly less quantity of KBA and was found by HPTLC method. ${ }^{37}$ developed and characterize lipid based drug delivery system of Boswellia serrata extract for enhancement of solubility in turn to enhance the oral absorption. Suitable composition for lipidic formulation were screened via solubility and compatibility studies. Concentration of AKBA and release of AKBA from formulation was estimated by HPTLC method using chloroform and methanol as mobile phase. The concentration of AKBA in gum resin extract and formulation was found to be $3.94 \pm 0.22$ and $0.95 \pm 0.17 \mathrm{w} / \mathrm{w}$ respectively. ${ }^{38}$ quantified boswellic acids content by HPTLC in the plant extract of BS by development of fingerprinting profiles of gum extract. Different solvents such as chloroform, methanol, and petroleum ether extracts were used for the fingerprint development. Linearity, correlation coefficient and least square regression equation was obtained by using peak area versus drug concentration from calibration curve. Different boswellic acids qualitatively and quantitatively in Boswellia extract were estimated by this analysis and this technique is able to separate the four boswellic acids in standard and samples. ${ }^{39}$ Pawar and his coworkers developed a simple, rapid and selective HPTLC method for quantitative estimation of BBA in different samples of Boswellia serrata (BS). Standard and samples spots of BBA were scanned at $530 \mathrm{~nm}$ wavelength. Recovery experiment was used for the establishment of the accuracy and reproducibility of the method. $100 \%$ mean recovery was obtained which indicates the accuracy of the method. ${ }^{40}$ Identified pure AKBA in Boswellia serrata extract [BSE] by HPTLC technique using tolueneethyl acetate 7:3 $(v / v)$ as mobile phase and aluminium plates coated with silica gel as stationary phase. Presence of single sharp peak (Rf value 0.52 ) confirmed the purity of AKBA extracted from BSE. ${ }^{41}$ Simple and rapid HPTLC method developed by for determination of $\mathrm{BA}$, curcumin and piperine content in herbal formulation prepared for the treatment of arthritis. Sharp and intense peaks were obtained by densitometric analysis for BA, curcumin and piperine ( $\mathrm{Rf}$ value of $0.61 \pm 0.03,0.48 \pm 0.02$ and $0.52 \pm 0.03$ respectively). Developed HPTLC method was found to be accurate and reproducible and it would be an effective tool in the quality control method for poly herbal formulations. ${ }^{42}$ separated and quantified BAs in BSE by HPTLC method. Separation of active BAs in the extract was done by TLC analysis by automated multiple development (AMD) using gradient method with the help of densitometric analysis. ${ }^{43}$

\section{High performance liquid chromatography}

In biological and chemical systems identification, estimation and separation of molecule and complexes of molecules is completed by use of advanced form of liquid chromatography recognized as High Performance Liquid Chromatography (HPLC). The technique, chromatography was originally developed by the Russian botanist M.S Tswett in 19031 but HPLC methods was appeared first time for the assay of bulk drug materials in 1980. Isolation, purification and standardization of herbal medicines in pharmaceutical industries are carried out by utilization of preparative and analytical HPLC methods. Basically low pressure HPLC especially under 5 bar and high pressure HPLC under pressure $>20$ bar have been employed for analysis of different components. Analytical and preparative HPLC is used for qualitative and quantitative estimation and isolation and purification of drug molecules respectively. Fast analysis, sensitivity and high resolution are the key parameters to be taken into consideration for effective qualitative and quantitative analysis by HPLC. ${ }^{44}$ 


\section{Advantages of HPLC}

- Sample resolution is high.

- Detection of very small sample quantity is possible by minimization of flow rates

- Small diameter (4.6mm), stainless steel, glass or titanium columns.

- HPLC can be used by normal and reverse phase methodology

- Column packing with very small $(3,5$ and $10 \mu \mathrm{m})$ particles.

- Well controlled flow rates and maintenance of relatively high inlet pressures provides efficient analysis of the samples

- Rapid qualitative and quantitative analysis of the samples. ${ }^{45}$

Studied comparative TLC and HPLC analysis on the composition of different dry and aqueous extracts of BS gum resin as a tool for the evaluation of the quality of the extracts. At $260 \mathrm{~nm}$, the majority of extracts presented two major peaks: the first one with retention time of $13.2 \mathrm{~min}$, and the second one, identified as AKBA by the use of an analytical standard, with retention time of $26 \mathrm{~min}$. Combination of TLC and HPLC analyses can be considered as a multidimensional analytical approach combining fast qualitative screening with an accurate and precise quantification of specific compounds. ${ }^{46}$ Sharma and his coworkers developed HPLC method for quantitative estimation of main BAs in BS gum resin extract. Various extraction processes were used by researchers for separation of BAs from gum resin. Calibration curves were plotted and showed good linear regression with $\mathrm{R}^{2}$ value of about 0.997 within the limits with good precision and overall recoveries. The developed HPLC method provides quantitative estimation of BAs in appreciable amounts in the marketed formulations and extracts. ${ }^{47}$ In another study prepared AKBA nano particles for the management of cerebral ischemia-reperfusion injury. HPLC method was used for the calculation of the encapsulation efficiency and loading capacity of prepared nano particles. Non-compartment model was used for the evaluation of pharmacokinetic parameters. Trapezoidal rule was used for the estimation of the area under plasma concentration time. ${ }^{48}$ further studied anti-inflammatory activity in the form of herbal gel for management of gout. The physicochemical properties of drug were evaluated on the basis of solubility, UV, FTIR, HPLC and DSC. Analysis of drug sample was done by HPLC technique with an attached UV detector, on a reverse phase column with Mobile phase in 90:10 ratio (Acetonitrile: water). The drug interaction FT-IR studies and DSC indicated that there was no chemical interaction between the drugs and the additives used in gel formulations. ${ }^{49}$ developed HPLC method for simultaneous estimation of BA and myristicin in herbal formulation used for the management of rheumatoid arthritis. Developed method was validated in terms of its accuracy, precision, selectivity, repeatability and recovery. Good linear correlation coefficients values for calibration curves were obtained $\left(r^{2}>0.995\right)$. Estimation of two marker compounds in market formulation was done with respect to boswellic acid and myristicin. The developed method leads to simultaneous determination of two markers in prepared formulation and marketed formulation. ${ }^{50}$ Moreover estimated concentration of different BAs extracted from callus cultures treated with different biotic and abiotic elicitors by HPLC method. HPLC chromatogram of standards with test samples were compared for retention time and peak area. ${ }^{51} \mathrm{~A}$ rapid and sensitive HPLC method was developed and validated for the quantitative analysis of BAs in formulation containing BSE by. The limit of detection and limit of quantification were found to be $(0.01740,0.05273,0.01739$ and $0.05270 \mathrm{mg}^{3} / \mathrm{mL}$ ) for $\alpha$ and $\beta$ boswellic acid, respectively. The developed HPLC method was successfully utilized for the assay of marketed preparations having BSE. ${ }^{52}$ Shah and his co-workers developed reverse phase HPLC method for the quantification of BAs present in extract of gum resin. Calibration curves were constructed for the quantification of components and retention time for KBA and AKBA was 4.3 and $7.11 \mathrm{~min}$ respectively. Developed method was highly useful for estimation of BAs and total run time was reduced by this method and makes it economically effective. ${ }^{53}$ explored pharmacokinetic parameters by using (Wok Vel.) BSE capsules. Twelve healthy adult men volunteers were selected for the study and KBA concentration was quantified in plasma by HPLC method. Different kinetic parameters were then calculated from the plasma concentrations of volunteers. ${ }^{54}$ HPLC method was employed for separation of BAs, from BSE as active constituents by Ganzera and Khan. Six BAs were accurately determined in the BSE and in multi constituents' formulation. Analysis of marketed products revealed considerable difference in the content of these pharmacologically active compounds in commercial samples. ${ }^{55-60}$ Various patents on HPLC technique are represented in Table 2.

\section{Liquid chromatography-mass spectroscopy}

LC-MS stands for Liquid chromatography-mass spectrometry is combination of two techniques and involves the principle of liquid chromatography or HPLC (phenomena of physical separation) along with mass spectroscopy (mass analysis of separating compounds). This technique possesses significant applications in the field of drug chemical analysis and powerful technique in terms of selectivity and sensitivity and frequently employed for pharmacokinetic evaluation of drug molecules in the field of bio analysis. ${ }^{61-64}$ Various merits of LCMS/MS are:

Significant combined effect of both liquid chromatography and mass spectroscopy for physical separation and identification of pharmaceuticals

\section{Detection limits are low}

Capability of generation of structural information

Having wide ability to analyze different polar and non polar analytes

Minimum quantity is required for sample analysis

Highly useful analytical technique for bio analysis. ${ }^{65,66}$

Measured BAs concentration in the blood and synovium of mice after treatment with topical or oral BAs by liquid chromatography/ mass spectrometry (LC/MS). Mouse model of osteoarthritis was used to find out whether topical or oral administration of BAs is useful for treatment of joint damage. Two to six fold higher synovial BAs concentrations was found of than that plasma of plasma concentration. ${ }^{67}$ compared bioavailability of BSE standardized soy lecithin formulation (Casperome ${ }^{\mathrm{TM}}$ ) with its corresponding non formulated extract. In the present study previously developed LC-MS/ MS method was used for the quantification of BAs. Enhanced BAs distribution in tissues with increased systemic availability increases possibilities of Casperome $\mathrm{TM}^{\mathrm{TM}}$ for further clinical development and make potential candidate for therapeutic use. ${ }^{68}$ To investigate the details whether BAs have high metabolism rate in the body, explored 
the pharmacokinetic evaluation of BAs in vitro in comparison with in vivo metabolic profiles of $\mathrm{KBA}$ and $\mathrm{AKBA}$ obtained after studies on animals (Rats). A rapid and sensitive LC-MS/MS method was developed resulted in effective better screening of metabolites. Human liver microsomes, rat liver microsomes and hepatocytes were used in the study and that KBA showed higher phase I metabolism rate than AKBA (means AKBA more stable toward phase I enzymes in comparison with KBA) ${ }^{69}$ Frank and Unger explored inhibiting property of cytochrome P450 (CYP) enzymes of different Boswellia species. Different Boswellia species (Boswellia serrata, Boswellia carteri, Boswellia frereana, and Boswellia sacra) are equally potent, non-selective inhibitors of the CYP enzymes. BAs extracted from commercially obtained frankincense samples were standardized by Electro Spray Ionization and tandem Mass Spectrometry (LC/LC/ ESI-MS) fingerprint analyses. Data obtained from study revealed that BAs could act as moderate to potent inhibitors of the applied CYP enzymes. ${ }^{70}$ used HPLC-DAD coupled to ESI-MS qualitative and quantitative analysis of BAs extracted from the gum resins of different species of Boswellia (B sacra and B serrata.) Coupling of HPLC with mass spectrometry allow the accurate identification and precise quantification of BAs in Boswellia extracts. ${ }^{71}$

Table 2 Patents on hplc used for boswellic acids characterization

\begin{tabular}{|c|c|c|c|c|}
\hline Patent no & $\begin{array}{l}\text { Filling } \\
\text { date }\end{array}$ & $\begin{array}{l}\text { Publication } \\
\text { date }\end{array}$ & Column & Patent title \\
\hline $\mathrm{EPI}|73| 62 \mathrm{Al}$ & $\begin{array}{l}28 \text { Apr, } \\
2000\end{array}$ & 23 Jan, 2002 & $(\mathrm{CI} 8250 \times 4.6 \mathrm{~mm})$ & $\begin{array}{l}\text { Compositions of boswellic acids derived from Boswellia } \\
\text { serrata gum resin, for treating lymphoproliferative and } \\
\text { autoimmune conditions } 56\end{array}$ \\
\hline US $20040073060 \mathrm{Al}$ & $\begin{array}{l}5 \text { Mar, } \\
2002\end{array}$ & 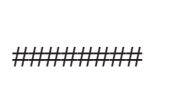 & $\begin{array}{l}\text { Cl8 column (Phenomenex, Luna, } \\
250 \mathrm{~mm} \times 21.2 \mathrm{~mm} \text {, }\end{array}$ & $\begin{array}{l}\text { Process for producing a fraction enriched up to } 100 \% \text { of } \\
3-0 \text {-Acetyl-II-keto-beta boswellic acid from an extract } \\
\text { containing a mixture of boswellic acids } 57\end{array}$ \\
\hline $\begin{array}{l}\text { Indian patent } \\
205269\end{array}$ & $\begin{array}{l}16 \text { Jan, } \\
2004\end{array}$ & 29 Jun, 2007 & $\begin{array}{l}\text { Cl } 8 \text { column (Phenomenex, Luna, } \\
250 \mathrm{~mm} \times 21.2 \mathrm{~mm}\end{array}$ & $\begin{array}{l}\text { A process for producing a fraction enriched up to } 100 \% \text { of } \\
3-0-\text { acetyl-II-keto-beta-boswellic acid from an extract } \\
\text { containing a mixture of boswellic acids } 58\end{array}$ \\
\hline WO20II080579 A2 & $\begin{array}{l}30 \mathrm{Dec} \\
2010\end{array}$ & 7-Jul-II & $\begin{array}{l}\text { Cl8 }(250 \times 4.6 \mathrm{~mm}, 5 \mathrm{~m}) \text { Phenomenex } \\
\text { column }\end{array}$ & A herbal composition for inflammatory disorders 59 \\
\hline EP2536288 Al & $\begin{array}{l}12, \mathrm{Apr} \\
2010\end{array}$ & $26 \mathrm{Dec}, 2012$ & Cl8 silica & $\begin{array}{l}\text { A novel Boswellia low polar gum resin extract and its } \\
\text { synergistic compositions } 60\end{array}$ \\
\hline WO20I5I66462 AI & $\begin{array}{l}30 \\
\text { Apr,2015 }\end{array}$ & 5 Nov, 2015 & - & $\begin{array}{l}\text { Method of purifying 3-o-acetyl-II-keto-beta-boswellic } \\
\text { acid (AKBA) 6I }\end{array}$ \\
\hline US9101599 B2 & $\begin{array}{l}\text { 14 Sep, } \\
2009\end{array}$ & II Aug, 2015 & $\begin{array}{l}\text { Phenomenex Luna Phenyl-Hexyl } \\
\text { analytical column }(4.6 \times 250 \mathrm{~mm}, 5 \mu)\end{array}$ & $\begin{array}{l}\text { Synergistic anti-inflammatory compositions comprising } \\
\text { Boswellia serrata extracts } 62\end{array}$ \\
\hline US9795646 B2 & $\begin{array}{l}5 \text { Aug, } \\
2014\end{array}$ & 24-Oct-17 & Reversed phase $\mathrm{Cl} 8$ silica column & $\begin{array}{l}\text { Boswellia oil, its fractions and compositions for enhancing } \\
\text { brain function } 63\end{array}$ \\
\hline
\end{tabular}

\section{Conclusion}

Utilization of herbal drug products industry is growing in a tremendous rate. Qualitative and quantitative analysis of natural drug products is fundamental step for their utilization in the field of medicine. Standardization and characterization ultimately affects the safe and effective use of herbal medicines. BAs obtained from herbal sources used have various therapeutic purposes including cancer. HPLC, HPTLC and LC/MS have been frequently used analytical techniques for identification and quantification of BAs.

\section{Acknowledgments}

None.

\section{Conflict of interest}

Authors declare that there is no conflict of interest.

\section{References}

1. Boligon AA, Athayde ML. Importance of HPLC in analysis of plants extracts. Austin Chromatogr. 2014;1(3):1-2.
2. Kamboj A. Analytical Evaluation of Herbal Drugs. Drug Discov Res Pharmacog. 2012;24-60.

3. Qurishi Y, Hamid A, Zargar MA, et al. Potential role of natural molecules in health and disease: Importance of boswellic acid. $J$ Med Plants Res. 2010;4(25):2778-2785.

4. Neeta Dureja H. Role of boswellic acids in cancer treatment. J Med Sci. 2014;14:261-269.

5. Choudhary N, Sekhon BS. An overview of advances in the standardization of herbal drugs. J Pharm Edu Res. 2011;2(2):55-70.

6. Rathod S, Patel NM, Patel PM. A review of modifications of analytical techniques in herbal research. Int $J$ Res Ayurveda Pharm. 2011;2:1483-1485.

7. Hussain H, Al-Harrasi A, Al-Rawahi A, et al. Chemistry and biology of essential oils of genus Boswellia. Evidence-Based Complement Alternat Med. 2013;1-12.

8. Rajput AP, Patil SY. Boswellia serrata Roxb. a boon of nature in the world of medicines: A review. European J Pharm Med Res. 2015;2:384-390.

9. Bhushan S, Kumar A, Malik F, et al. A triterpenediol from Boswellia serrata induces apoptosis through both the intrinsic and extrinsic 
apoptotic pathways in human leukemia HL-60 cells. Apoptosis 2007;12(10):1911-1926.

10. Sharma A, Chhikara S, Ghodekar SN, et al. Phytochemical and pharmacological investigations on Boswellia serrata. Pharmacog Rev. 2009;3(5):206-215.

11. Sharma S, Thawani V, Hingorani L, et al. Pharmacokinetic study of 11Keto- $\boldsymbol{\beta}$ Boswellic Acid. Phytomed. 2004;11(3):255-260.

12. Hamidpour R, Hamidpour S, Hamidpour M. Chemistry, pharmacology and medicinal property of frankincense (Boswellia species) from the selection of traditional applications to the novel phytotherapy for the prevention and treatment of serious diseases. Global J Med Res. $2015 ; 15: 15-22$.

13. Eichhorn T, Greten HJ, Efferth T. Molecular determinants of the response of tumor cells to Boswellic acids. Pharmaceuticals. 2011;4(8):1171-1182.

14. Bairwa K, Jachak SM. Development and optimisation of 3Acetyl-11-keto- $\boldsymbol{\beta}$-boswellic acid loaded poly-lactic-co-glycolic acid-nanoparticles with enhanced oral bioavailability and in-vivo antiinflammatory activity in rats. J Pharm Pharmacol. 2015;67(9):1188-97.

15. Nikam PH, Kareparamban J, Jadhav A, et al. Future trends in standardization of herbal drugs. J Appl Pharm Sci. 2012;2:38-44.

16. Phani RS, Prasad KRS, Mallu UR. Scientific approach for RP-HPLC method development: Complete review. Int J Sci Innov Discov. 2012;2:218-228

17. Kokare NV, Wadkar KA, Kondawar MS. Review of standardization of herbal churna. Int J Res Ayurveda Pharm. 2014;5:397-401.

18. Siddiqui MZ. Boswellia serrata, A potential anti-inflammatory agent: An overview. Indian J Pharm Sci. 2011;73(3):255-61.

19. Folashade KO, Omoregie EH, Ochogu AP. Standardization of herbal medicines-A review. Int J Biodivers Conserv. 2012;4:101-112.

20. Thakkar K, Parmar V, Patel D. Recent advances in herbal drug standardization-A review. Int J Adv Pharm Res. 2013;4:2130-2138.

21. Mohammad A, Bhawani SA, Sharma S. Analysis of herbal products by thin-layer chromatography: A review. Int J Pharma Bio Sci. 2010;1(2):1-50.

22. Gangwal A. Extraction, Estimation and thin layer chromatography of tannins: A review. Int J Pharm Chemical Sci. 2013;2:1585-1588.

23. Vani MM, Rao PSG, Varma GN, et al. Identification and chemical characterization of Azadirachta indica leaf extracts through thin layer chromatography. Int J Res Engineering and Technol. 2016;5:117-122.

24. Gocan S, Cimpan G. Review of the analysis of medicinal plants by TLC: Modern approaches. J Liquid Chromatog \& Related Technol. 2004;27:1377-1411.

25. Chavan M, Sutar M, Deshmukh S. Significance of various chromatographic techniques in drug discovery and development. Int $J$ Res Pharm Chem. 2013;3:282-289.

26. Kumar S, Jyotirmayee K, Sarangi M. Use of fingerprinting and marker compounds for the identification and standardization of Boswellia serrata gum extract. Int J Pharm Sci Rev Res. 2013;18:126-132.

27. Lade BD, Patil AS, Paikrao HM, et al. Comprehensive working, principles and applications of thin layer chromatography. Res J Pharm Biol Chemical Sci. 2014;5:486-503.

28. Gupta V, Jain1 ADK, Gill NS, et al. Development and validation of HPLC method-a review. Int Res J Pharm Appl Sci. 2012;2:17-25.
29. Siddiqui MR, Alothman ZA, Rahman N. Analytical techniques in pharmaceutical analysis: A review. Arabian J Chem. 2017;10:S1409S142.

30. Sivaraj C, sripriya R, Antioxidant activities and thin layer chromatographic analysis of aqueous extract of tubers of Drynaria quercifolia (L)JSm. Free Radicals and Antioxidants. 2018;8:26-31.

31. Shah SA, Rathod IS, Suhagia BN, et al. Estimation of boswellic acids from market formulations of Boswellia serrata extract and 11-keto $\beta$-boswellic acid in human plasma by high-performance thin-layer chromatography. J Chromatogr B. 2007;848(2):232-238.

32. Shivatare RS, Nagore DH, Nipanikar SU. HPTLC' an important tool in standardization of herbal medical product: A review. J Sci Innovat Res. 2013;2:1086-1096.

33. Andola HC, Purohit VK. High performance thin layer chromatography (HPTLC): A modern analytical tool for biological analysis. Nat Sci. 2010;8:58-61.

34. Kasar R, Gogia A, Shah K, et al. Critical factor that governs a successful TLC/HPTLC analysis of herbal medicinal products (HMPS Research and Reviews. Res Rev J Pharm Anal. 2013;2:1-8.

35. KumarV, Kamle P, MithalA. High performance thin layer chromatography (HPTLC): A review. Int J Anal Bioanal Chem. 2014;4:42-44.

36. Bimal N, Sekhon BS. Thin layer Chromatography: Application in Pharmaceutical Science. Ph Tech Med. 2013;2:323-333.

37. Mehta M, Satija S, Garg M. Comparison between HPLC and HPTLC densitometry for the determination of $11-$ keto- $\beta$-boswellic acid and $3-$ acetyl-11-keto- $\beta$-boswellic acid from Boswellia serrata extract. Indian J Pharm Edu Res. 2016;50:418-423.

38. Bhardwaj A, Dwivedi H, Kymonil KM, et al. Solubility enhancement of Boswellia serrata Roxb ex Colebr Extract through a self dispersible lipidic formulation approach. Indian $J$ Natural Prod Resource. 2016;7(1):9-18.

39. Kamal YT, Yusufoglu H, Alharthy S. Use of fingerprinting and marker compounds for the identification and standardization of Boswellia serrata gum extract. Int J Biol Pharm Allied Sci. 2014;3:2290-2303.

40. Pawar RK, Sharma S, Singh KC, et al. Development and validation of HPTLC method for the determination of $\boldsymbol{\beta}$ boswellic acid from Boswellia serrata Roxb. (Exudate). Asian J Pharm Clin Res. 2011;4:72-76.

41. Goel A, Ahmad FJ, Singh RM, et al. Anti-inflammatory activity of nanogel formulation of 3-Acetyl-11-Keto- $\boldsymbol{\beta}$-Boswellic acid. Pharmacologyonline. 2009;3:311-318.

42. Vaykole AM, Nirmal SA, Jadhav RS, et al. Development and validation of HPTLC method to detect curcumin, piperine, and boswellic acid in polyherbal transdermal patch. J Liquid Chromatogr Related Technol. 2014;37:367-378.

43. Olga NP, Ivanova SA, Alexander NS, et al. Separation and quantification of terpenoids of Boswellia serrata Roxb. extract by planar chromatography techniques (TLC and AMD). J Separat Sci. 2006;29(14):2245-2250.

44. Azim Md S, Mitra M, Bhasin PS. HPLC method development and validation: A review. Int Res J Pharm. 2013;4:39-46.

45. Sasidharan S, Chen Y, Saravanan D, et al. Extraction, isolation and characterization of bioactive compounds from plants' extracts. Afr $J$ Tradit Complement Altern Med. 2011;8(1):1-10.

46. Beghelli D, Isani G, Roncada $\mathrm{P}$, et al. Antioxidant and ex vivo immune system regulatory properties of Boswellia serrata extracts. Oxid Med Cell Longev. 2017;1-17. 
47. Sharma N, Bhardwaj V, Singh S, et al. Simultaneous quantification of triterpenoic acids by high performance liquid chromatography method in the extracts of gum resin of Boswellia serrata obtained by different extraction techniques. Chem Central J. 2016;10:1-10.

48. Ding Y, Qia Y, Wang M, et al. Enhanced neuroprotection of Acetyl-11Keto- $\beta$-Boswellic Acid (AKBA)-loaded O-carboxymethyl chitosan nano particles through antioxidant and anti-inflammatory pathways. $\mathrm{Mo}$ Neurobiol. 2016;53(6):3842-3853.

49. Pal P, Shams S, Alam S. Formulation and evaluation of herbal gel of Boswellia serrata for the management of gout. Int J Pharm Res Scholar. 2014;3:242-250.

50. Jain RA, Rajput SJ, Raval RR. Development and validation of RP-HPLC method for determination of boswellic acid and myristicin in commercial herbal formulation. Int J Pharm Pharma Sci. 2013;5:379-383.

51. Ghorpade RP, Chopra A, Nikam TD. Influence of biotic and abiotic elicitors on four major isomers of boswellic acid in callus culture of Boswellia serrata Roxb. Plant Omics J. 2011;4:169-176.

52. Wandahre MD, Deokate UA, Khadabadi SS, et al. Comparative estimation of $(\alpha+\beta)$ boswellic acid and curcumin from marketed herbal antirheumatic tablets. Asian J Chem. 2010;22:5883-5890.

53. Shah SA, Rathod IS, Suhagia BN, et al. Estimation of boswellic acids from market formulations of Boswellia serrata extract and 11-keto $\beta$-boswellic acid in human plasma by high-performance thin-layer chromatography. J Chromatogr Sci. 2007;848(2):232-238.

54. Sharma S, Thawani V, Hingorani L, et al. Pharmacokinetic study of 11Keto- $\boldsymbol{\beta}$ Boswellic Acid. Phytomedicine. 2004;11(3):255-260.

55. Ganzera M, Khan IA. Reversed phase high performance liquid chromatography method for the analysis of boswellic acids in Boswellia serrata. Planta Med. 2001;67(8):778-780.

56. Vladimir B, Muhammed M. Compositions of boswellic acids derived from Boswellia serrata gum resin, for treating lymphoproliferative and autoimmune conditions. Nigeria; 2002.

57. Gokaraju GR, Gokaraju RR, Gottumukkala VS, et al. Process for producing a fraction enriched up to $100 \%$ of 3-0-Acetyl-11-keto-beta boswellic acid from an extract containing a mixture of boswellic acids. India; 2004

58. Gokaraju GR. A process for producing a fraction enriched up to $100 \%$ of 3-o-acetyl-11-keto-beta-boswellic acid from an extract containing a mixture of boswellic acids. India; 2007.
59. Paramesh R, Babu UV. Herbal composition for inflammatory disorders. India; 2011.

60. Gokaraju GR. A novel boswellia low polar gum resin extract and its synergistic compositions. India; 2012.

61. AL-Harrisi A, Hussain J, Ali L. Method of purifying 3-o-acetyl-11keto-beta-boswellic acid. India; 2015.

62. Gokaraju GR. Synergistic anti-inflammatory compositions comprising Boswellia serrata extracts. India; 2015.

63. Gokaraju GR. Boswellia oil, its fractions and compositions for enhancing brain function. India; 2017.

64. Patel, D. Matrix effect in a view of L-MS/MS: an overview. Int J Pharma and Bio Sci. 2011;2:559-564.

65. Ferrera Z, Santana CM, Rodriguez JJS. New developments in liquid chromatography mass spectrometry for the determination of micropollutants. Chromatogr Res Int. 2012;1-18.

66. Murugan S, Pravallika N, Sirisha P, et al. A review on bioanalytical method development and validation by using LC-MS/MS. J Chem Pharma Sci. 2013;6:41-45.

67. Wang Q, Pan X, Wong HH, et al. Oral and topical boswellic acid attenuates mouse osteoarthritis. J Osteoarthritis Cartilage. 2014;22(1):128-132.

68. Hüsch J, Bohnet J, Fricker G, et al. Enhanced absorption of boswellic acids by a lecithin delivery form (Phytosome $\left.{ }^{\circledR}\right)$ of Boswellia extract. Fitoterapia. 2013;84:89-98.

69. Kruger P, Daneshfar R, Eckert GP, et al. Metabolism of boswellic acids in vitro and in vivo. Drug Metabol Dispos. 2008;36(6):1135-1142.

70. Frank A, Unger M. Analysis of frankincense from various Boswellia species with inhibitory activity on human drug metabolising cytochrome P450 enzymes using liquid chromatography mass spectrometry after automated on-line extraction. J Chromatogr A. 2006;1112(2):255-262.

71. Mannino G, Occhipinti A, Maffei ME. Quantitative Determination of 3-O-Acetyl-11-Keto- $\boldsymbol{\beta}$-Boswellic Acid (AKBA) and Other Boswellic Acids in Boswellia sacra Flueck (syn B carteri Birdw) and Boswellia serrata Roxb. Molecules. 2016;21(10):1-8. 